\title{
Cytoskeletal Organization of Porcine Oocytes Aged and Activated Electrically or by Sperm
}

\author{
Hiroyuki SUZUKI ${ }^{1)}$, Yoko TAKASHIMA ${ }^{1)}$ and Koji TOYOKAWA ${ }^{1)}$ \\ ${ }^{1)}$ Faculty of Agriculture and Life Sciences, Hirosaki University, Hirosaki 036-8561, Japan
}

\begin{abstract}
The role and interaction of microtubules and microfilaments, which are important for progressing the events during oocyte maturation and activation, are not well understood. This study was designed to examine the cytoskeletal changes of the porcine oocyte activated electrically or by sperm with relation to the effects of oocyte aging and the paternal and maternal contributions. During electric activation, fusion of the first polar body (PBI) into the oocyte was attempted to evaluate changes in the cytoskeleton induced by incorporation of maternal chromatin in comparison with penetrated sperm (paternal) chromatin. Aged oocytes matured for 50-60 h displayed an elongated spindle and a less dense distribution of microfilaments compared to young oocytes matured for $44 \mathrm{~h}$. Oocytes were effectively activated with double electric pulses regardless of aging (93-100\%). Fusion of PBI into the oocyte declined with oocyte aging (from $52 \%$ to $22 \%$ ). When fusion occurred, PBI chromatin was incorporated into the microtubule networks of the ooplasm and was frequently transformed into one "extra" nuclear-like structure. Young parthenotes possessed one microtubulerich domain including one or more pronuclei. In aged parthenotes, however, the cortical and cytoplasmic microfilaments decreased in density, resulting in frequent fragmentation of eggs. In zygotes, male and female pronuclei were included in separate domains of microtubules, respectively, anchored by microfilaments. The present results suggest that the instability of cytoskeleton of the oocyte induced by aging may increase egg fragmentation and that there may be a difference between the paternal and maternal contributions to the cytoskeletal reorganization during pronuclear formation and migration.
\end{abstract}

Key words: Porcine oocyte, Aging, Electric activation, IVF, Cytoskeleton

(J. Reprod. Dev. 48: 293-301, 2002)

D uring mammalian oocyte maturation and fertilization, many dynamic events occur to ensure successful development. These include the resumption of meiosis, chromosome condensation, spindle formation, polar body emission, sperm incorporation and pronuclear formation and migration. Cytoskeleton organization is well known to be important for the progression of these events in mammals such as the mouse [1-4], rat [5], rabbit [6], sheep [7, 8], cattle [9, 10], pig [11-15] and human [16]. Our previous studies showed that

Accepted for publication: January 31, 2002

Correspondence: H. Suzuki cytoskeletal alteration is involved in the dynamic change of the cumulus-oocyte cell communication during oocyte maturation, and that the cumulus mass condition affects oocyte maturation in the pig $[17,18]$.

Observations of the early events of fertilization have indicated the paternal inheritance of a microtubule-organizing center in oocytes of rabbits [6], sheep [7], cattle [9], and pigs [12-15, 19]. In pig oocytes, sperm aster enlarged during sperm decondensation and extended throughout the cytoplasm at the time of pronuclear apposition [12, 13]. Recent reports have described the origin of the active microtubule-organizing center as paternally 
derived and its role in pronuclear migration and apposition in cattle [9] and pigs [13, 15]. Studies on parthenogenesis have also shown that a dense network of microtubules appears at the pronuclear stage after artificial activation in these species [1013]. Kim et al. [12] suggested that sperm contributes to the centrosome during fertilization in the pig, but the interaction of the paternal and maternal chromatin with the organization of microtubules and microfilaments is not completely understood. For further understanding of this issue, we examined the distribution and dynamics of microtubules and microfilaments in porcine oocytes matured in vitro, aged, and activated parthenogenetically or by sperm. Especially, we compared the nuclear and cytoskeletal behavior between two types of oocytes: oocytes in which the first polar body (PBI) was electrically fused back; and oocytes penetrated by sperm. This approach will help us to understand the mechanism whereby chromatin of paternal or maternal origins is associated with the organization of microtubules and microfilaments of the ooplasm.

\section{Materials and Methods}

In vitro maturation and aging of oocytes

In vitro maturation of pig oocytes was based on the procedures reported in our previous study [17]. Briefly, oocytes were aspirated from antral follicles (2-5 $\mathrm{mm}$ in diameter) of ovaries collected from slaughtered prepubertal gilts. After being washed with Dulbecco's phosphate buffered saline containing $0.1 \%$ polyvinyl alcohol (DPBS-PVA), groups of 10-15 oocytes were transferred to NCSU23 medium supplemented with $10 \%(\mathrm{v} / \mathrm{v})$ porcine follicular fluid, 10 i.u./ml eCG (Teikoku Hormone Mfg. Co. Ltd., Tokyo, Japan) and 10 i.u./ $\mathrm{ml}$ hCG (Mochida Pharmaceutical Co. Ltd., Tokyo, Japan). The oocytes were cultured for $24 \mathrm{~h}$, then incubated in NCSU23 without hormonal supplements for a total period of 44,50 or $60 \mathrm{~h}$ in an atmosphere of $5 \% \mathrm{CO}_{2}$ in air at $39 \mathrm{C}$.

\section{Electric activation of oocytes}

Matured and aged oocytes were electrically stimulated. Oocytes were denuded of cumulus cells with $0.1 \%$ hyaluronidase, washed, and MIIarrested oocytes were identified by the presence of the PBI under a stereomicroscope and the maturation rate was recorded. Before activation, they were equilibrated for $5 \mathrm{~min}$ in pulse medium: $0.3 \mathrm{M}$ mannitol supplemented with $0.1 \mathrm{mM} \mathrm{CaCl}_{2}$, $0.1 \mathrm{mM} \mathrm{MgCl} 2$ and $0.05 \%$ bovine serum albumin (BSA). Electric pulses were delivered with an Electro Cell Fusion (Bex LF101L, Tokyo, Japan). The chamber for electric stimulation was made of a glass Petri dish (60 $\mathrm{mm}$ in diameter) with two parallel platinum block electrodes spaced $1 \mathrm{~mm}$ apart and half-filled with pulse medium. One oocyte was placed between the electrodes and the cleavage plane of PBI was oriented perpendicularly to the line between both electrodes. The oocyte was stimulated with double DC pulses $(150 \mathrm{~V} / \mathrm{mm}$ for $60 \mu \mathrm{sec}) 1 \mathrm{sec}$ apart, washed twice, and incubated in $100 \mu \mathrm{l}$-drops of NCSU23 medium supplemented with $0.4 \%$ BSA under mineral oil in an atmosphere of $5 \% \mathrm{CO}_{2}$ in air at $39 \mathrm{C}$ for $6 \mathrm{~h}$. Oocytes were then stained for fluorescence and considered activated when progressed to the pronuclear stage. Oocytes of each aging group, incubated for an additional $6 \mathrm{~h}$ with or without mannitol treatment, were also examined.

\section{In vitro fertilization (IVF)}

Sperm-rich fractions of ejaculates were collected from three Landrace boars, kept at $17 \mathrm{C}$ for $20 \mathrm{~h}$, and washed three times. Spermatozoa were preincubated in modified Tris-buffered medium [20] supplemented with $1 \mathrm{mM}$ Caffeine and $0.1 \%$ BSA (IVF medium) for $90 \mathrm{~min}$. Oocytes matured for $44 \mathrm{~h}$ were washed three times and placed in 50$\mu \mathrm{l}$ droplets of IVF medium. Sperm fraction $(50 \mu \mathrm{l})$ was introduced to the droplet of oocytes. The oocytes were then co-cultured with spermatozoa at a final concentration of $2 \times 10^{5}$ cells $/ \mathrm{ml}$ for $6 \mathrm{~h}$ at $39 \mathrm{C}$ in an atmosphere of $5 \% \mathrm{CO}_{2}$ in air. Oocytes were then transferred to $100-\mu \mathrm{l}$ droplets of NCSU medium and cultured for an additional $6 \mathrm{~h}$.

\section{Fluorescence observations}

Methods for preparing samples for fluorescence observations have been reported previously [17, 18]. Briefly, denuded oocytes were fixed in a microtubule stabilization buffer [21] at $37 \mathrm{C}$ for $1 \mathrm{~h}$, washed extensively and blocked overnight at $4 \mathrm{C}$ in the wash medium (calcium-free DPBS containing $2 \%$ BSA, $2 \%$ goat serum, $0.2 \%$ milk powder, $0.2 \%$ sodium azide and $0.1 \%$ Triton- $\mathrm{X}$ ). Afterwards, the fixed samples were then exposed overnight (at $4 \mathrm{C}$ ) to anti- $\beta$ tubulin primary antibodies (1:200; Sigma 
Chemical Co., MO, USA), washed, and then incubated with fluorescein isothiocyanate (FITC)conjugated secondary antibody (1:200; Sigma) at $37 \mathrm{C}$ for $2 \mathrm{~h}$. After rinsing, the samples were stained with rhodamine-phalloidin (1:1000; Molecular Probes, Eugene, OR, USA) for microfilaments for $1 \mathrm{~h}$, washed again, then stained for DNA with Hoechst $33342(10 \mu \mathrm{g} / \mathrm{ml})$ in mounting medium containing PBS and glycerol (1:1). The oocytes were finally mounted on slides and examined to assess the nuclear configuration and the distribution of microtubules and microfilaments.

The samples were viewed under an Olympus microscope (BX-FLA, Olympus, Tokyo, Japan). A U-MNIBA filter set (Olympus) was used for FITC, a U-MWIB set (Olympus) was used for rhodamine, and a U-MWU set (Olympus) for Hoechst. A cooled CCD video system (ImagePoint, Photometrics Ltd., Tucson, AZ, USA) was used to obtain images on a computer and color adjustment was performed by IPLab-Spectrum P software (Signal Analytics Corporation, Vienna, VA, USA).

\section{Data analysis}

Data were assessed by analysis of variance with the help of the BMDP program (BMDP Statistical Software, Inc., Los Angeles, CA). When appropriate, percentage data were arcsined transformed. Differences between the means were determined using Duncan's multiple range test. A value of $\mathrm{P}<0.05$ was considered to be statistically significant.

\section{Results}

Parthenogenetic activation of aged oocytes

Based on the presence of PBI, the overall maturation rate of the oocytes was $89.1 \%$ in this study. Rates of activation after different treatments are summarized in Table 1. Spontaneous activation did not occur even after incubation for as long as 66 h. Mannitol treatment induced parthenogenetic activation of porcine oocytes at a higher rate in the oocytes matured for 50 and $60 \mathrm{~h}(58 \%$ and $33 \%$, respectively) than in those matured for $44 \mathrm{~h}(6 \%)$. After double electric stimuli, high activation rates were obtained irrespective of the maturational age of the oocytes (93-100\%). However, a larger number of pronuclear oocytes became fragmented as the oocyte age increased.

Table 2 shows the types of parthenotes produced. Different types of parthenotes, which were not previously described by Kaufman [22], were observed in this study; namely, due to electric fusion, the chromatin of PBI origin was incorporated into the oocyte. In the majority of the cases $(82 \%, 62 \%$ and $83 \%$ for $44-, 50-$ and $60-\mathrm{h}$ groups, respectively), an "extra" large nuclear-like structure were formed in the ooplasm; otherwise scattered chromosomes of PBI origin were noted. The "extra" nucleus of PBI origin was easily distinguishable by its size and orientation in the cell from the pronucleus of oocyte origin. When not fused with PBI, the proportion of the eggs having two pronuclei increased in the 50- and 60-h groups (Table 2). The fusion rate of PBI and the oocyte was significantly reduced by oocyte aging: $52 \pm 9 \%, 22 \pm$

Table 1. Pronuclear formation and fragmentation of porcine oocytes of different maturational age

\begin{tabular}{|c|c|c|c|c|c|c|c|}
\hline \multicolumn{2}{|c|}{ Treatment* } & \multirow[t]{2}{*}{$\begin{array}{c}\text { Age of } \\
\text { oocytes (h) }\end{array}$} & \multirow{2}{*}{$\begin{array}{c}\text { No.of } \\
\text { oocytes } \\
\text { examined }\end{array}$} & \multirow{2}{*}{$\begin{array}{c}\text { Mean } \% \text { of } \\
\text { activated } \\
\text { oocytes }\end{array}$} & \multicolumn{3}{|c|}{$\begin{array}{l}\text { Mean } \% \text { of activated } \\
\text { oocytes showing** }\end{array}$} \\
\hline $\mathrm{M}$ & $\mathrm{EP}$ & & & & PPN & $\mathrm{PN}$ & Frag \\
\hline- & - & 44 & 34 & 0 & - & - & - \\
\hline - & - & 50 & 38 & 0 & - & - & - \\
\hline- & - & 60 & 40 & 0 & - & - & - \\
\hline+ & - & 44 & 33 & $6 \pm 6^{a}$ & 0 & 100 & 0 \\
\hline+ & - & 50 & 38 & $58 \pm 14^{b}$ & $19 \pm 10$ & $64 \pm 9$ & $17 \pm 9$ \\
\hline+ & - & 60 & 39 & $33 \pm 9^{\mathrm{ab}}$ & $11 \pm 11$ & $44 \pm 13$ & $45 \pm 23$ \\
\hline+ & + & 44 & 36 & 100 & $17 \pm 2$ & $83 \pm 2^{\mathrm{a}}$ & 0 \\
\hline+ & + & 50 & 38 & $93 \pm 5$ & $5 \pm 5$ & $86 \pm 6^{\mathrm{a}}$ & $9 \pm 3^{a}$ \\
\hline+ & + & 60 & 39 & $96 \pm 4$ & 0 & $59 \pm 1^{b}$ & $41 \pm 1^{\mathrm{b}}$ \\
\hline
\end{tabular}

Means from three replicates. ${ }^{*}, \mathrm{M}$, mannitol; EP, electric pulses. ${ }^{* *}$, Percentage of oocytes against activated oocytes. PPN, prepronuclear stage; PN, pronuclear stage; Frag, pronucleated, but fragmented. ${ }^{\mathrm{a}, \mathrm{b}}$, Figures with different superscripts are significantly different in each treatment group. 
Table 2. Types of parthenotes after electric stimulation of porcine oocytes of different maturational age

\begin{tabular}{|c|c|c|c|c|c|c|c|c|}
\hline \multirow{4}{*}{$\begin{array}{c}\text { Ageof } \\
\text { oocytes } \\
\text { (h) }\end{array}$} & \multirow{4}{*}{$\begin{array}{c}\text { No. of } \\
\text { oocytes } \\
\text { activated }\end{array}$} & \multicolumn{7}{|c|}{ Percentage of the oocytes showing*: } \\
\hline & & \multicolumn{3}{|c|}{ PBI not incorporated } & \multicolumn{4}{|c|}{ PBIincorporated } \\
\hline & & \multirow[t]{2}{*}{$1 \mathrm{PN}+\mathrm{PBII}$} & \multirow{2}{*}{$1 \mathrm{PN}$} & \multirow{2}{*}{$2 \mathrm{PN}$} & \multicolumn{2}{|c|}{$2 \mathrm{PN}$} & \multicolumn{2}{|c|}{$\geq 3 \mathrm{PN}$} \\
\hline & & & & & $+\mathrm{PBII}$ & -PBII & $+\mathrm{PBII}$ & -PBII \\
\hline 44 & 36 & $34 \pm 5^{\mathrm{ab}}$ & $10 \pm 6$ & $5 \pm 3^{\mathrm{a}}$ & $14 \pm 5$ & $18 \pm 10^{\mathrm{a}}$ & 0 & $20 \pm 7^{\mathrm{a}}$ \\
\hline 50 & 36 & $43 \pm 13^{\mathrm{a}}$ & $13 \pm 10$ & $22 \pm 5^{\mathrm{b}}$ & $10 \pm 4$ & $5 \pm 5^{\mathrm{b}}$ & $3 \pm 3$ & $5 \pm 3^{b}$ \\
\hline 60 & 37 & $20 \pm 12^{b}$ & $19 \pm 8$ & $26 \pm 9^{b}$ & $9 \pm 5$ & $12 \pm 4^{\mathrm{ab}}$ & $3 \pm 3$ & $12 \pm 4^{\mathrm{ab}}$ \\
\hline
\end{tabular}

Means from three replicates. *, PN, pronucleus(-ei); PBI, the first polar body; +/-PBII, with or without the second polar body. ${ }^{\mathrm{a}, \mathrm{b}}$, Figures with different superscripts are significantly different.
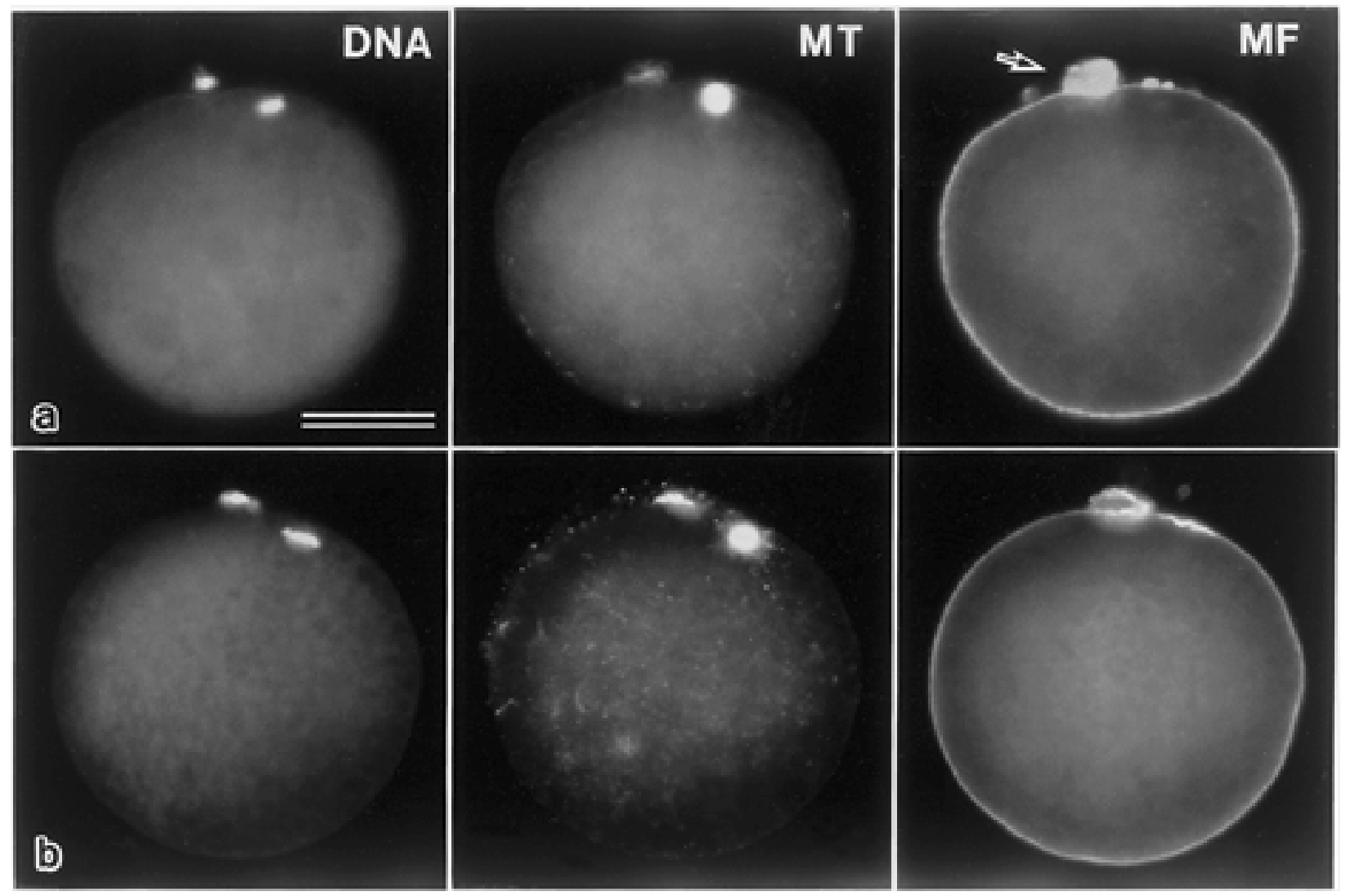

Fig. 1. Metaphase II oocytes triple stained to visualize chromatin (DNA), microtubules (MT) and microfilaments (MF). Bar represents $50 \mu \mathrm{m}$. The first polar body is located at the 12 o'clock position of the oocyte and the metaphase plate is on the right side in a and b. (a) $44 \mathrm{~h}$ maturation. Microtubules are observed in the meiotic spindle at the cell cortex. Microfilaments are noted mainly just under the plasma membrane of the oocyte and the polar body (arrow). (b) $60 \mathrm{~h}$ maturation. Tubulin cohered to thicker filaments can be seen throughout the ooplasm. Cortical microfilaments have decreased in staining intensity compared to Fig.1a.

$11 \%$ and $35 \pm 6 \%$ for $44-, 50$ - and 60 -h groups, respectively.

\section{Changes in the cytoskeleton organization}

During oocyte aging: At the metaphase of the second meiotic division (MII), microtubules were mainly located in the meiotic spindle (Fig. 1a). The MII spindle was located peripherally in the ooplasm, with its long axis perpendicular to the surface of the oocyte, and contained condensed chromosomes at the equatorial plate. The pole-topole length of the spindle was significantly 
Table 3. Sizes of meiotic spindle in porcine oocytes matured in vitro

\begin{tabular}{|c|c|c|c|}
\hline \multirow{2}{*}{$\begin{array}{l}\text { Age of } \\
\text { oocytes } \\
\text { (h) }\end{array}$} & \multirow{2}{*}{$\begin{array}{c}\text { No. of } \\
\text { oocytes } \\
\text { examined }\end{array}$} & \multicolumn{2}{|c|}{ Sizes of meiotic spindle* } \\
\hline & & $\begin{array}{l}\text { Pole-to-pole } \\
\text { length }\end{array}$ & $\begin{array}{l}\text { Equator } \\
\text { width }\end{array}$ \\
\hline 44 & 34 & $6.9 \pm 0.2^{\mathrm{a}}$ & $8.2 \pm 0.3$ \\
\hline 50 & 38 & $7.5 \pm 0.4^{\mathrm{a}}$ & $9.5 \pm 1.2$ \\
\hline 60 & 40 & $9.0 \pm 0.7^{\mathrm{b}}$ & $10.8 \pm 1.0$ \\
\hline
\end{tabular}

*, Mean \pm s.e.m. $(\mu \mathrm{m})$. are significantly different $(\mathrm{P}<0.05)$.

increased in oocytes incubated for $60 \mathrm{~h}$ compared to younger oocytes, although no significant difference was found in the width of the equatorial plate (Table 3). Tubulin was also faintly stained throughout the cytoplasm of the oocytes matured for $44 \mathrm{~h}$, whereas in the aged oocytes the cytoplasmic tubulin cohered to thick filaments in $13 \%(n=40)$ and $21 \%(n=38)$ of oocytes matured for 50 and $60 \mathrm{~h}$, respectively (Fig. 1b). Such tubulin cohesion was more evident after an additional $6 \mathrm{~h}$ maturation incubation: $42 \%(n=36)$ and $83 \%(n=36)$ of oocytes matured for 50 and $60 \mathrm{~h}$, respectively.

Microfilaments were uniformly distributed in the ooplasm and strongly stained in the cortex and on the contact surfaces of the oocyte and PBI. After incubation for 50 or $60 \mathrm{~h}$, the incidence of the oocytes with less dense distribution of microfilaments in the ooplasm, especially the cortex, was increased $(23 \%, n=40$ and $63 \%, n=38$ for 50 and $60 \mathrm{~h}$ of culture, respectively). In $3(8 \%)$ out of 38 oocytes incubated for $60 \mathrm{~h}$, the microfilament domain within the ooplasm was separated into several aggregates of various sizes, showing division of the microfilament domain (photo not shown).

After electric activation: A representative picture of a pronuclear oocyte after electric pulses is shown in Fig. 2a. A dense interphase microtubule network appeared after pronuclear formation, which was concentrated around the pronucleus. In electrically activated parthenotes, one microtubule domain included all pronuclei, irrespective of the number of pronuclei formed, and the cortical microfilaments were decreased in density compared to those of MII oocytes. In the aged parthenotes, the microtubule-rich domain was located at the center of the ooplasm and microfilaments also concentrated around the microtubule domain.
After fertilization: At $6 \mathrm{~h}$ post-insemination, the oocyte penetrated by a spermatozoon showed two domains of microtubules of female and male pronuclei, respectively (Fig. 2b). Microfilaments were noticed between the two microtubule domains. When female and male pronuclei had migrated into the center of the zygote at $12 \mathrm{~h}$ postinsemination, one domain of microtubules included both pronuclei and microfilaments were concentrated around the microtubule domain. Polyspermic eggs at early stages of fertilization were also observed, where small domains of microtubules were evidenced by tubulin staining around pronuclei derived from each incorporated sperm head (Fig. 2c). At $12 \mathrm{~h}$ post-insemination, each microtubule domain in the polyspermic zygote had not always merged and created one large domain occupying almost all of the ooplasm.

\section{Discussion}

The present results showed that the meiotic spindle of the porcine oocyte is peripherally located and radially oriented with its long axis as seen in other domestic species [6, 8, 10] and humans [16], and no rotation of the meiotic spindle occurred unlike in laboratory rodents $[3,5]$. Further, the meiotic spindle is barrel-shaped in the pig ([11] and this study) and cattle [10], and is approximately 10 $\mu \mathrm{m}$ long, whereas in laboratory rodents it is much more elongated and tapered $[5,23]$ with a length of $26.4 \pm 0.3 \mu \mathrm{m}$ in the mouse [23] and $16.4 \pm 0.7 \mu \mathrm{m}$ in the hamster (our unpublished observation). In the present study, the pole-to-pole length of the meiotic spindle increased significantly during oocyte aging, as reported for the aged bovine oocyte [24]. In contrast, the spindle length reduces in aged mouse oocytes [23]. These differences in cytoskeletal behavior and characteristics might reflect speciesspecific differences in the nature of the meiotic spindle [25].

During oocyte aging, peripheral microfilaments, which are involved in anchorage of the spindle to the oocyte cortex $[8,12-15,26]$, drastically reduced in density as observed here. Kim et al. [11] observed that the meiotic plate was frequently located outside of the microfilament-rich domain in aged pig oocytes. Similar features were also observed in mouse oocytes [26]. Such changes in the microfilament architecture may be related to a 


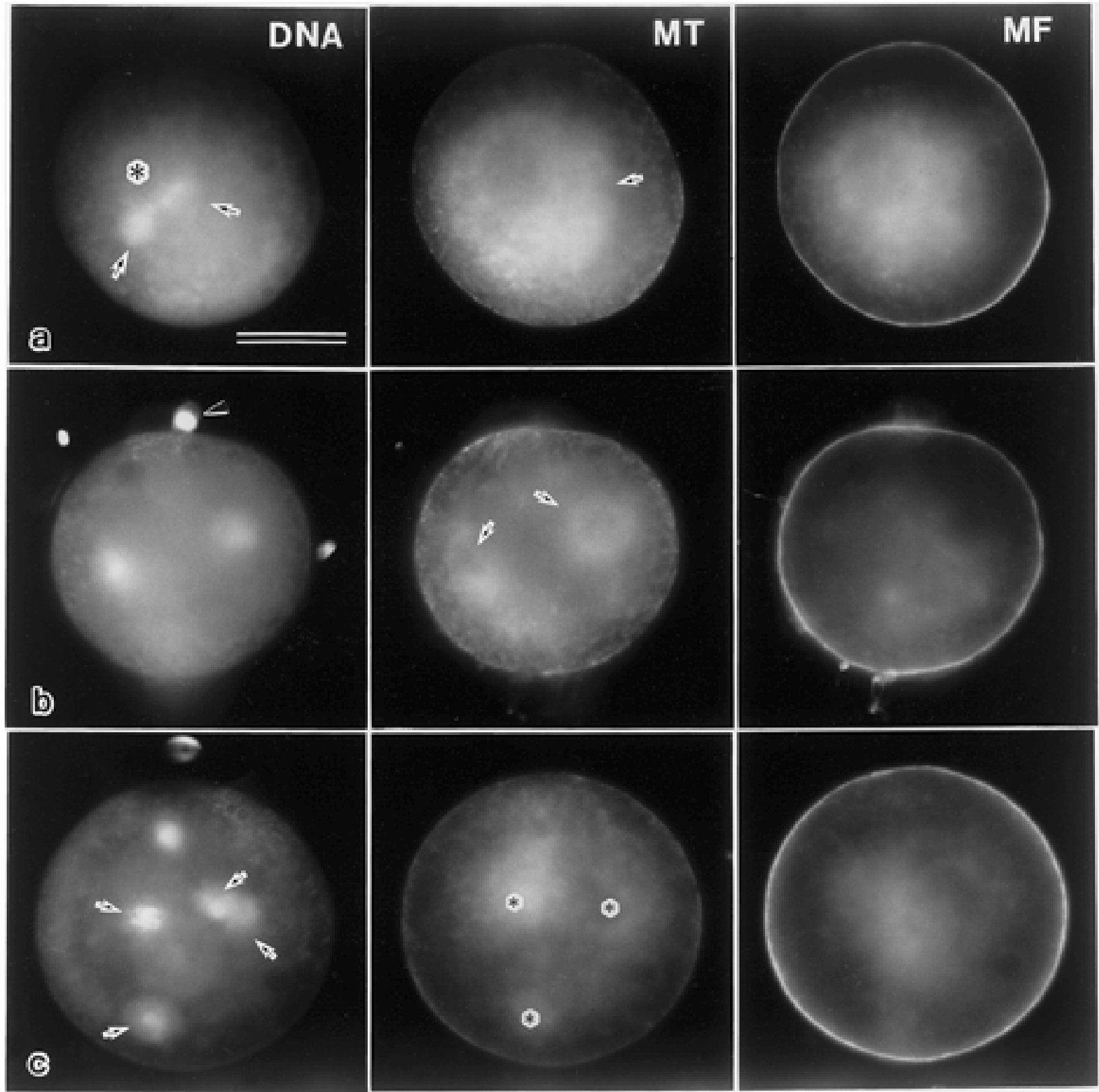

Fig. 2. Pronuclear oocytes triple stained to visualize chromatin (DNA), microtubules (MT) and microfilaments (MF). Bar represents $50 \mu \mathrm{m}$. (a) An electrically activated oocyte of which the first polar body is fused. DNA staining shows three (pro)nuclear-like structures: a large one is incorporated with the first polar body (out of focus, asterisk) and the other two small ones are of oocyte origin (arrows). One microtubule domain includes all nuclei (arrow) and microfilaments are also concentrated around the nuclei. (b) A monospermic oocyte with the second polar body (arrowhead). Female and male pronuclei are included within different domains of microtubules (arrows). Microfilaments are located between two microtubule domains. (c) A polyspermic oocyte penetrated by four spermatozoa (arrows). At least three domains of microtubules are recognizable by tubulin staining around the pronuclei on this focus plane (asterisks). Microfilaments are concentrated around the microtubule domain.

low incidence of PBII emission in aged eggs (Table 2 ), since the PB extrusion is dependent on the cytoskeletal organization $[2,15]$. The loss of anchoring capacity for the microtubule spindle pole and/or the instability of the microtubule assembly in the spindle might explain the elongation of the spindle, resulting in malsegregation of chromosomes in the aged oocytes. 
In the present study, very high activation rates were obtained irrespective of oocyte aging. Hagan et al. [27] also reported a similar result. By contrast, Kim et al. [11] showed that the activation rate was higher in aged oocytes than in younger oocytes. This discrepancy may be due to differences in the number and strength of electric stimulations employed. We applied double DC pulses of $150 \mathrm{~V} /$ $\mathrm{mm}$ for $60 \mu \mathrm{sec}$ for activation. Since mannitol treatment can activate a greater number of aged oocytes than younger oocytes, aged oocytes might be more sensitive to high concentrations of calcium and magnesium solution. Together, the treatment with double DC pulses seems to be more effective at inducing parthenogenetic activation in young porcine oocytes compared to the single pulse employed by Kim et al. [11]. Unlike in cattle in which aged oocytes are readily activated, but not frequently fragmented [28-32], the aged pig oocytes fragmented as oocyte age increased. A very similar result was obtained when aged mouse oocytes were activated by ethanol [26]. The present actin staining revealed that patchy aggregation of microfilaments occurred in the ooplasm of aged parthenotes, and is probably a phenomenon associated with the egg fragmentation. Recently, Kikuchi et al. [33] have shown that a decrease in maturation/M-phase promoting factor (MPF) activity during prolonged culture causes increased fragmentation in aged porcine oocytes, as well as an increased ability for parthenogenetic activation. In our unpublished observation, treatment with 6dimetylaminopurin, a protein phosphorylation inhibitor, caused not only a high incidence of parthenogenetic activation (80-100\% for $44 \mathrm{~h}$ - to 60 h-incubation groups) but also increased fragmentation in young and aged porcine oocytes $(66 \%, 88 \%$ and $96 \%$ for $44 \mathrm{~h}, 50 \mathrm{~h}$ and $60 \mathrm{~h}$ groups, respectively). Therefore, the kinase activity of MPF may play important role(s) in preventing egg fragmentation as suggested recently [33]. It is suggested, therefore, that aged porcine oocytes are not suitable for recipient cytoplasts in nuclear transfer programs, due to their frequent fragmentation under the present activation procedure.

The present study shows that electric stimulation can cause the fusion of the PBI into the oocyte, affecting the type of parthenotes. Interestingly, the chromatin of PBI was easily incorporated into the microtubule networks of the oocytes after cell fusion, frequently transforming into one "extra" nuclear-like structure, but very rarely two "extra" structures (Table 2). It is assumed that an interphase network of microtubules, probably derived from the maternal centrosome retained after the second meiotic division [12], is distributed in the ooplasm and includes the pronucleus of the maternal origin. On the contrary, in the early stage of fertilization (at $6 \mathrm{~h}$ post-insemination), female and male pronuclei were incorporated in two different domains of microtubules, respectively. These microtubule domains were anchored to the microfilament architecture, which was located between them. During polyspermy, multiple male pronuclei were found in separated microtubule domains, suggesting that the formation of the microtubule domain is associated with each incorporated sperm head and tail in the zygote. A similar situation was described by Szollosi and Hunter [19] and Kim et al. [12], who reported the formation of one sperm aster per penetrated sperm during polyspermic fertilization in the pig. It is known that the paternal centrosome is active during fertilization in the pig, sheep and cattle [7,9]. From the present observation, the sperm aster may develop into a microtubule-rich domain including the male pronucleus as seen in monospermic and polyspermic zygotes. This is the main difference between the zygote and the parthenote. During pronuclear migration in the monospermic zygotes at $12 \mathrm{~h}$ post-insemination, one microtubule domain included female and male pronuclei, suggesting a union of microtubule domains of paternal and maternal origin. Microfilaments were distributed around this merged microtubule domain. Similarly, different microtubule domains in the polyspermic zygote merged in some cases, but the centration of multiple pronuclei did not occur. These observations suggest that the assemblies and interactions of microtubules and microfilaments may be disturbed by the presence of multiple male pronuclei, but not by the presence of multiple female pronuclei.

In conclusion, the instability of cytoskeleton of the oocyte induced by aging is associated with egg fragmentation after activation treatment. Different mechanism(s) are involved in the formation of the microtubule-rich domain including the female or male pronucleus in the early stage of fertilization. Moreover, it is suggested that multiple pronuclei of paternal and maternal origin may exert different 
effects on cytoskeletal reorganization during the pronuclear formation and migration.

\section{Acknowledgements}

The authors thank the staff of the Gene Research
Center at Hirosaki University for the use of the image analyzing system and the staff of the Inakadate Meat Inspection Office (Aomori, Japan) for supplying pig ovaries.

\section{References}

1. Maro B, Johnson MH, Pickering SJ, Flach G. Changes in actin distribution during fertilization of the mouse egg. J Embryol Exp Morph 1984; 81: 211237.

2. Maro B, Johnson MH, Webb M, Flach G. Mechanism of polar body formation in the mouse oocyte: an interaction between the chromosomes, the cytoskeleton and the plasma membrane. J Embryol Exp Morph 1986; 92: 11-32.

3. Schatten G, Simerly C, Schatten H. Microtubule configurations during fertilization, mitosis, and early development in the mouse and the requirement for egg microtubule-mediated motility during mammalian fertilization. Proc Natl Acad Sci USA 1985; 82: 4152-4156.

4. Schatten H, Simerly C, Maul G, Schatten G. Microtubule assembly is required for the formation of the pronuclei, nuclear lamin acquisition, and DNA synthesis during mouse, but not sea urchin, fertilization. Gamete Res 1989; 23: 309-322.

5. Zernicka-Goetz M, Kubiak JZ, Antony C, Maro B. Cytoskeletal organization of rat oocytes during metaphase II arrest and following abortive activation: A study by confocal laser scanning microscopy. Mol Reprod Dev 1993; 35: 165-175.

6. Yllera-Fernandez MDM, Crozet N, Ahmed-Ali M. Microtubule distribution during fertilization in the rabbit. Mol Reprod Dev 1992; 32: 271-276.

7. Le Guen P, Crozet N. Microtubule and centrosome distribution during sheep fertilization. Eur J Cell Biol 1989; 48: 239-249.

8. Le Guen $\mathbf{P}$, Crozet $\mathbf{N}$, Huneau D, Gall L. Distribution and role of microfilaments during early events of sheep fertilization. Gamete Res 1989; 22: 411-425.

9. Long CR, Pinto-Correia C, Duby RT, Ponce De Leon FA, Boland MP, Roche JF, Robl JM. Chromatin and microtubule morphology during the first cell cycle in bovine zygotes. Mol Reprod Dev 1993; 36: 23-32.

10. Navara CS, First NL, Schatten G. Microtubule organization in the cow during fertilization, polyspermy, parthenogenesis and nuclear transfer: the role of sperm aster. Dev Biol 1994; 162: 29-40.

11. Kim N-H, Moon S-J, Prather RS, Day BN.
Cytoskeletal alteration in aged porcine oocytes and parthenogenesis. Mol Reprod Dev 1996; 43: 513-518.

12. Kim N-H, Simerly C, Funahashi H, Schatten G, Day BN. Microtubule organization in porcine oocytes during fertilization and parthenogenesis. Biol Reprod 1996; 54: 1397-1404.

13. Kim N-H, Chung K-S, Day BN. The distribution and requirements of microtubules and microfilaments during fertilization and parthenogenesis in pig oocytes. J Reprod Fertil 1997; 111: 143-149.

14. Wang WH, Abeydeera LA, Prather RS, Day BN. Polymerization of nonfilamentous actin into microfilaments is an important process for porcine oocyte maturation and early embryo development. Biol Reprod 2000; 62: 1177-1183.

15. Sun Q-Y, Lai L, Park K-W, Kühholzer B, Prather RS, Schatten H. Dynamic events are different mediated by microfilaments, microtubules, and mitogen-activated protein kinase during porcine oocyte maturation and fertilization in vitro. Biol Reprod 2001; 64: 879-889.

16. Pickering SJ, Johnson MH, Braude PR, Houliston E. Cytoskeletal organization in fresh, aged and spontaneously activated human oocytes. Hum Reprod 1988; 3: 978-989.

17. Suzuki H, Jeong B-S, Yang X. Dynamic changes of cumulus-oocyte cell communication during in vitro maturation of porcine oocytes. Biol Reprod 2000; 63: 723-729.

18. Suzuki H, Takashima Y, Toyokawa K. Influence of incubation temperature on meiotic progression of porcine oocytes matured in vitro. J Mamm Ova Res 2001; 18: 8-13.

19. Szollosi D, Hunter RHF. Ultrastructural aspects of fertilization in the domestic pig: sperm penetration and pronuclear formation. J Anat 1973; 116: 181-206.

20. Abeydeera LR, Day BN. Fertilization and subsequent development in vitro of pig oocytes inseminated in a modified Tris-buffered medium with frozen-thawed ejaculated spermatozoa. Biol Reprod 1997; 57: 729-734.

21. Allworth AE, Albertini DF. Meiotic maturation in cultured bovine oocytes is accompanied by remodeling of the cumulus cell cytoskeleton. Dev 
Biol 1993; 158: 101-112.

22. Kaufman MH. Mammalian parthenogenesis: background to experimental studies, terminology and pathways of development. In: Kaufman MH. (ed.), Early Mammalian Development: Parthenogenetic Studies. Cambridge: Cambridge Univ. Press; 1983: 1-19.

23. Eichenlaub-Ritter U, Chandley AC, Gosden RG. Alterations to the microtubular cytoskeleton and increased disorder of chromosome alignment in spontaneous ovulated mouse oocytes aged in vivo: an immunofluorescence study. Chromosoma 1986; 94 : 337-345.

24. Liu L, Ju J-C, Yang X. Parthenogenetic development and protein patterns of newly matured bovine oocytes after chemical activation. Mol Reprod Dev 1998; 49: 298-307.

25. Lee J, Miyano T, Moor RM. Spindle formation and dynamics of tubulin and nuclear mitotic apparatus protein distribution during meiosis in pig and mouse oocytes. Biol Reprod 2000; 62: 1184-1192.

26. Webb M, Howkett S, Maro B. Parthenogenesis and cytoskeletal organization in ageing mouse eggs. $J$ Embryol Exp Morph 1986; 95: 131-145.

27. Hagen RD, Prather RS, First NL. Response of porcine oocytes to electrical and chemical activation during maturation in vitro. Mol Reprod Dev 1991; 28: 70-73.

28. Nagai T. Parthenogenetic activation of cattle follicular oocytes in vitro with ethanol. Gamete Res 1987; 16: 243-249.

29. Ware CB, Barnes FL, Maiki-Laurila M. First NL. Age-dependence of bovine oocyte activation. Gamete Res 1989; 22: 265-275.

30. Yang $X$, Jiang $\mathbf{S}$, Farrell $\mathbf{P}$, Foote $\mathbf{R H}$ and McGrath AB. Nuclear transfer in cattle: Effect of nuclear donor cells, cytoplast age, co-culture, and embryo transfer. Mol Reprod Dev 1993; 35: 29-36.

31. Presicce GA, Yang $\mathbf{X}$. Nuclear dynamics of parthenogenesis of bovine oocytes matured in vitro for 20 and $40 \mathrm{hr}$ and activated with combined ethanol and cycloheximide treatment. Mol Reprod Dev 1994; 37: 61-68.

32. Suzuki H, Liu L, Yang X. Age-dependent development and surface ultrastructural changes following electrical activation of bovine oocytes. Reprod Fertil Dev 1999; 11: 159-165.

33. Kikuchi K, Naito K, Noguchi J, Shimada A, Kaneko H, Yamashita M, Aoki F, Tojo H, Toyoda Y. Maturation/M-phase promoting factor: A regulator of aging in porcine oocytes. Biol Reprod 2000; 63: 715-722. 